\title{
Obesity Prevention and National Food Security: A Food Systems Approach
}

\author{
Lila Finney Rutten, ${ }^{1,2}$ Amy Lazarus Yaroch, ${ }^{3}$ Heather Patrick, ${ }^{4}$ and Mary Story ${ }^{1}$ \\ ${ }^{1}$ Division of Epidemiology, Department of Health Sciences Research, Mayo Clinic, 200 First Street SW, Rochester, MN 55905, USA \\ ${ }^{2}$ Division of Epidemiology and Community Health, School of Public Health, University of Minnesota, 1300 S 2nd Street, Suite 300, \\ Minneapolis, MN 55454, USA \\ ${ }^{3}$ Gretchen Swanson Center for Nutrition, 505 Durham Research Plaza, Omaha, NE 68105, USA \\ ${ }^{4}$ Health Behaviors Research Branch, National Cancer Institute, 6130 Executive Boulevard, MSC 7335, Bethesda, MD 20892, USA
}

Correspondence should be addressed to Lila Finney Rutten, rutten.lila@mayo.edu

Received 19 October 2012; Accepted 6 November 2012

Academic Editors: C. Banwell, E. Lokkegaard, and A. Rosano

Copyright (c) 2012 Lila Finney Rutten et al. This is an open access article distributed under the Creative Commons Attribution License, which permits unrestricted use, distribution, and reproduction in any medium, provided the original work is properly cited.

\begin{abstract}
Interventions that cultivate sustainable food systems to promote health, prevent obesity, and improve food security have the potential for many large-scale and long-lasting benefits including improvements in social, environmental, health, and economic outcomes. We briefly summarize findings from previous research examining associations between obesity and food insecurity and discuss the need for greater synergy between food insecurity initiatives and national obesity prevention public health goals in the United States. The common ground between these two nutrition-related public health issues is explored, and the transformation needed in research and advocacy communities around the shared goal of improving population health through individual, environmental, and policy level changes to promote healthy sustainable food systems is discussed. We propose an ecological framework to simultaneously consider food insecurity and obesity that identifies levers for change to promote sustainable food systems to improve food security and prevent obesity.
\end{abstract}

\section{Introduction}

The burdens of obesity and food insecurity are unequally distributed in the USA population, with shared risk factors rendering certain socioeconomic and racial and ethnic subgroups at greater risk for both [1-3]. The intersection of obesity and food insecurity in the USA points to a public health imperative for scientists, practitioners, and policy makers to document and address food system inadequacies and leverage existing social programs to simultaneously address the nutrition issues of obesity and food insecurity [3]. Both food insecurity and obesity are increasingly recognized as forms of malnutrition resulting from poor dietary quality (higher intakes of nutrient-poor energy-dense foods) [4]. Food insecurity and obesity stem from a shared food system, therefore, corrective action must be taken within the underlying system from which they derive $[5,6]$.

In this paper, we briefly discuss findings from research examining associations between food insecurity and obesity in the United States (USA) and emphasize the need for greater synergy between food insecurity policies and initiatives and national public health goals around obesity prevention. We identify the common ground between these nutrition-related public health issues and call for a broadening of scope in the research and advocacy communities to align efforts around the shared goal of improving the health of at risk populations. We propose an ecological framework that identifies levers for change within the physical and social aspects of food systems to guide simultaneous attention to the pressing public health problems of food insecurity and obesity.

\section{Obesity and Food Insecurity}

Although obesity and food insecurity historically have been viewed as distinct public health issues, there has been increasing interest in understanding the seemingly paradoxical association between obesity and food insecurity, with escalating public health concern over the dual burden of food insecurity and obesity shouldered by certain populations $[3,7,8]$. 
Rates of obesity have steadily increased in the USA over the past several decades, increasing dramatically among adult, child and adolescent populations [9-16]. Recent estimates from the National Health and Nutrition Examination Survey indicate that over one-third of the USA adult population is obese $[12,15]$. Similar data from the National Survey of Children's Health indicate that approximately 16\% of USA children are obese [17]. Obesity and related chronic disease are significant contributors to preventable morbidity and mortality and current population trends in obesity threaten to stall or reverse trends toward greater health and longevity in the USA population $[9,16,18-20]$.

Food security is defined by the United States Department of Agriculture (USDA) as having access to enough food for all household members, at all times, to lead active, healthy lives [1, 21-23]. Households wherein members experience uncertainty around obtaining enough food due to insufficient resources are considered food insecure [21, 23]. Food-insecure households may experience low food security or very low food security. Households experiencing low food security often avoid substantially disrupting their eating patterns by engaging in coping strategies such as eating less varied diets, participating in federal food assistance programs, and accessing community feeding programs [1, 21-24]. Households experiencing very low food security lack sufficient resources to obtain food, which disrupts the normal eating patterns of one or more household members [1, 21-23].

Evidence from research examining the nature of the relationship between food insecurity and risk of obesity in children and adolescents is somewhat mixed [3, 7, 8, 25-37]. Recent meta-analytic reviews and research syntheses identify a relationship between food insecurity and obesity among certain subpopulations such as households with incomes below the poverty line, households led by a single adult, and households headed by African American and/or Hispanic persons $[1,38,39]$. Regardless of whether a causal association exists between food insecurity and obesity, growing evidence documents a coexistence of these nutrition-related problems [3]. Thus, collaborative efforts to prevent obesity and eradicate food insecurity in the USA are needed $[3,5,6]$.

The overlap in risk factors for obesity and food insecurity is undeniable $[3,11,32,33,38,40-43]$. Current evidence documents an excess burden of food insecurity and an excess burden of obesity among households living in poverty $[2,3,40,44]$. Differential access and affordability of more nutritious food options (e.g., fruits and vegetables) have been proposed as potential contributors to existing health disparities and the higher rates of diet-related chronic disease and obesity experienced by low-income and racial ethnic minority populations [45]. The term "food desert" has been used to describe geographic areas with limited access to affordable and nutritious food. Populations at greatest risk for obesity, including those living in food deserts, are also at increased risk for experiencing food insecurity [1, 46, 47].

Efforts to address obesity and food insecurity in the USA have often been singular, yet parallel. For instance, obesity prevention efforts include the "Let's Move" campaign, as well as the push by federal and philanthropic organizations to reverse the trend of childhood obesity by 2015; concurrently there are separate initiatives to alleviate or end childhood hunger, including the pledge by President Obama to end childhood hunger by 2015. Nutrition-relevant policy changes and interventions should simultaneously attend to issues of food insecurity and obesity to ensure that efforts to control obesity do not create additional burden for those struggling with food insecurity or put more households at risk for food insecurity $[3,5]$. It is equally important that efforts to reduce food insecurity do not inadvertently contribute to the obesity epidemic through provision of nutrient-poor, energy-dense foods [3].

\section{Food Assistance Initiatives and Public Health Nutrition Goals}

Evidence linking participation in food assistance programs and obesity has been mixed and fraught with methodological limitations [3, 48, 49]. The growing obesity epidemic in the USA, coupled with the disproportionate burden of obesity and related chronic disease shouldered by populations who access food assistance programs, represents a public health imperative to leverage existing food assistance programs and other resources to support the health and well-being of disadvantaged populations [3].

The USDA directs 15 food and nutrition programs in the USA, assisting approximately one in four Americans each year [24]. The five largest USDA administered domestic food and nutrition assistance programs include the Supplemental Nutrition Assistance Program (SNAP), the National School Lunch Program, the Special Supplemental Nutrition Program for Women, Infants, and Children (WIC), the Child and Adult Care Food Program, and the School Breakfast Program [24]. During fiscal year 2010, each of these programs expanded, proving a nutritional safety net to an increasingly food insecure population [24]. SNAP, formerly known as food stamps, was initiated in the 1960 s and expanded in the 1970s to address growing rates of underconsumption and inadequate nutrient intake and is now the largest food assistance program in the USA. In 2010, SNAP served approximately 44.7 million people each month [50].

Despite increasing population reliance on federal food assistance programs, the most significant nutrition-related public health problem in the USA population today has shifted from one of deficiency to one of excess; rates of overweight and obesity and associated chronic disease have grown at an alarming rate in the USA population over the past three decades, particularly among low-income ethnic minority populations [48]. Existing evidence documents an excess burden of obesity among populations with lower socioeconomic position and among food insecure populations [2, 38-40, 44]. Interest in identifying policy and programmatic actions to address this public health disparity is mounting [5].

The disproportionately higher incidence of overweight and obesity and associated chronic disease among certain low-income populations has stimulated public health researchers and policy makers to explore ways in which food 
assistance programs, such as SNAP, might be modified to improve the dietary quality of recipients and thereby prevent or reduce obesity [49]. Proposals to facilitate and/or place restrictions on the types of foods that can be purchased with food supplement benefits (e.g., increased fruits and vegetables and decreased sugar sweetened beverages), to provide incentives for buying more healthful foods, and to expand nutrition education efforts have been suggested as means to support improvements in dietary quality among recipients to reduce risk factors for obesity and related chronic disease [51]. Improvements in federal food assistance programs, including the income supplement for the purchase of fruits and vegetables in the SNAP Healthy Incentive Program, Electronic Benefit Transfer (EBT), and Double Up Food Bucks Programs to promote purchase and consumption of local produce at farmers markets, modification of the WIC food package to include vouchers for fruits and vegetables and changes to meals in the National School Lunch Program to adhere to USDA nutrition guidelines, heed the call for greater synergy in efforts to reduce obesity and improve food security [27].

\section{Public Health Goals and Research Priorities around Obesity and Food Insecurity}

Current public health goals around obesity prevention are beginning to reflect an understanding of the power of public policy and environmental change to influence both individual- and population-level behavioral change while acknowledging the importance of promoting population food security as part of such efforts. Implementation of public policy at a macrolevel, including local, state, or federal legislation, is an effective and comprehensive means to affect change in population behavior. Policy-level changes influence the environments that subsequently influence the behavior and choices of individuals. Effective public health policy and environmental change can encourage populations to practice more healthful behavior [52]. That is, effective policies can change environments to have improved access (and lower costs) to healthier foods and to subsequently make the healthy choice the easy or default choice [52-57].

The Nutrition and Weight Status objectives identified for Healthy People 2020 are centered on an overarching goal to promote health and reduce chronic disease risk through healthful diets and maintenance of healthy body weights [58]. The stated objectives emphasize that efforts to improve diet and reduce obesity require attention to the policies and environments that support individual behavior across a variety of settings. Increasing household food security and eliminating food insecurity are specified in the Healthy People 2020 objectives as integral to goals of promoting healthful diets and healthy weight [58].

Responding to the growing childhood obesity epidemic, the White House Task Force on Childhood Obesity developed and is working to implement an interagency plan to eliminate child obesity [59]. The Task Force published an action plan with specific recommendations for addressing the childhood obesity epidemic, including a call for further research and related policy to address food insecurity [59]. During the first year of this initiative, the Healthy, HungerFree Kids Act was enacted to expand children's access to healthy school meals [60]. This act aims to increase the number of eligible children enrolled in school meal programs through direct certification of children who receive other federal assistance and improve access to nutritious meals in schools [60].

The National Institutes of Health (NIH) has also convened an Obesity Research Task Force to develop a strategic plan to accelerate multidisciplinary research efforts to address the population burden of obesity and related chronic disease. The task force identified and recently published a series of research challenges and opportunities to inform NIH research planning [61]. Importantly, the NIH Strategic Plan for Obesity Research explicates the need to integrate research results into community programs and clinical practice [61]. Historically, this need has not plainly taken into account food insecurity. However, given the congruency in population health goals around chronic disease prevention and overlap in risk factors and mechanisms, it is apparent that efforts to promote food security should be woven more closely with obesity prevention.

\section{A Food Systems Approach to Reducing Food Insecurity and Preventing Obesity}

Public health advocates have long sought to unify food assistance efforts with high-quality nutrition. Focused attention on how current food system policies and practices may impact public health and diet-related chronic disease and obesity is essential to developing a systematic strategy that simultaneously achieves community food justice and public health success $[5,6]$. The American Public Health Association has defined a sustainable food system as "one that provides healthy food to meet current food needs while maintaining healthy ecosystems that can also provide food for generations to come with minimal negative impact to the environment. A sustainable food system also encourages local production and distribution infrastructures and makes nutritious food available, accessible, and affordable to all." [62]. Furthermore, per the Healthy People 2020 Nutrition and Weight Status objectives, greater attention to food insecurity, food systems, and food justice is encouraged in public health efforts to reduce or prevent obesity [58].

Our call for a systematic approach to simultaneously address the pressing public health issues of food insecurity and obesity points to an opportunity that is ripe for the integration of the existing evidence and further strategic development of the science around food insecurity and obesity to inform public policy and community programs about food with concurrent consideration of both issues [5, 6]. Efforts to close the gap between science and public policy around food security and obesity will require changes in both the research and advocacy communities to align efforts around the shared goal of improving the health and wellbeing of at-risk populations $[5,6]$. Strategic science aimed at changing public understanding of the link between food 
insecurity and obesity coupled with science-based efforts to inform agricultural and nutrition legislation, policy and regulations offers a useful paradigm for harnessing obesity prevention and nutrition science to change public policy with relevance to food security.

Typical approaches to public health problems with behavioral or lifestyle components, such as obesity and food insecurity, have focused mainly on individual change through motivational or educational interventions. This approach, as applied at the intersection of food insecurity and obesity, has been a failed experiment. Despite decades of individual-focused interventions for obesity and expansion of investments in nutrition education for food assistance recipient [58], we have not reversed the trend of either condition. To effectively reduce the public health burden of obesity in food insecure populations, science and advocacy efforts must align focus on systemic and environmental factors to cultivate "optimal defaults" for individual nutrition-related behavior by making the healthful option the easy option. \{Thaler, 2008 number 51\}. An example of an optimal default may be placing fruits and vegetables at the front of school cafeteria lines to make them more accessible or including apple slices as the "default" side dish instead of French fries in children's meals.

The processes underlying food insecurity and obesity derive from a shared food system [5]. Therefore, efforts to address food insecurity and obesity must emulate the complexity of the system from which they emerge. The food systems concept describes the required inputs, processes, and generated outputs involved in the provision of food and nutrients for sustenance and health including growing, harvesting, processing, packaging, transporting, marketing, consuming, and disposing of food $[63,64]$. A set of shared food system principles supporting economically, ecologically, and socially sustainable food systems that promote the health of individuals, communities, and the environment have been developed through the cooperative efforts of the Academy of Nutrition and Dietetics (formerly the American Dietetic Association), the American Nurses Association, the American Planning Association, and the American Public Health Association [65]. Accordingly, health-promoting food systems are defined as those that support the physical and mental health of producers and consumers with accountability for the public health impact across the food system including production, processing, packaging, labeling, distribution, consumption, and disposal. Sustainability of food systems thus derives from the conservation and regeneration of natural resources and biodiversity to manage current food and nutrition requirements with transparency and equity in process and outcomes without compromising future system efficacy and output $[63,64]$. Health-promoting and sustainable food systems are necessarily diverse in size and scale, geography, and culture to ensure resiliency in the face of ecological and economic challenges and to promote diversity and equity in the availability of healthful food options $[63,64]$.

Adopting a food systems approach facilitates awareness of the complexity of food systems and of the social, economic, environmental, and political contexts within which they operate $[63,64]$. Aligning food assistance initiatives with public health nutrition goals requires a systematic approach to simultaneously address food insecurity and obesity through research and practice efforts aimed at establishing sustainable food systems to promote health, improve food security, and prevent obesity [5]. Individual, environmental, and policy level changes to promote the development of healthy sustainable food systems that simultaneously address the nutrition-related public health goals of obesity prevention and food security are needed.

\section{Levers for Change in the Macro- and Micro-Food System Environments}

Several opportunities exist for cultivating greater synergy between public health efforts around food insecurity and obesity prevention. Delineation of areas for potential intervention and public health impact can be organized according to the ecological perspective inherent in the food systems approach. Specifically, priorities for addressing shared risk factors and health outcomes in obesity prevention and food security can be identified and operationalized according to the size and nature of the environments in which intervention is to be implemented. This approach, originally described as the analysis grid for environments linked to obesity, conceptualizes environments in terms of size and type to identify potential interventions [66].

This ecological approach can be adapted and expanded to conceptualize the shared physical, economic, political, and sociocultural environments of obesity and food insecurity and to identify levers for change and opportunities for intervention that may impact individual behavior (see Table 1). Within this framework, macroenvironmental sectors describe the greater influencing context of industry and supporting infrastructure on available and consumed food options [66]. For example, macroenvironmental sectors relevant to the food environment may include food production and manufacturing, distribution, and marketing as well as relevant technological and social infrastructure. The framework describes microenvironmental settings as the settings that involve food where people gather for specific purposes [66]. Examples of microenvironments include homes, schools, workplaces, community venues, food service or retail outlets (e.g., supermarkets, restaurants, etc.), and healthcare settings. Within both macroenvironmental sectors and microenvironmental settings, several environmental types with relevance to obesity prevention and food insecurity have been identified including the physical environment, the economic environment, the political environment, and the sociocultural environment [66]. We examine each of these types, in turn, to identify effective interventions to concurrently address obesity and food insecurity.

6.1. Physical Food Environment. The physical food environment refers to the availability of food outlets, relevant training opportunities, and nutrition-related information within specific settings (e.g., supermarkets, communities, schools, etc.) [66]. Identifying levers for change within 
TABLE 1: Levers for change in the macro- and microenvironments to influence obesity in food insecure populations.

\begin{tabular}{|c|c|c|c|c|}
\hline & \multicolumn{4}{|c|}{ Environment type } \\
\hline & Physical & Economic & Political & Sociocultural \\
\hline $\begin{array}{l}\text { Macroenvironmental } \\
\text { settings }\end{array}$ & $\begin{array}{l}\text { Modify agricultural, } \\
\text { housing, transportation, } \\
\text { and social policies that } \\
\text { influence food } \\
\text { production and } \\
\text { distribution. }\end{array}$ & $\begin{array}{l}\text { Offer monetary } \\
\text { incentives for healthy } \\
\text { food options (e.g., } \\
\text { subsidies) and } \\
\text { disincentives for } \\
\text { unhealthy options (e.g., } \\
\text { taxes). }\end{array}$ & $\begin{array}{l}\text { Promote agricultural, } \\
\text { social, and food security } \\
\text { and nutrition policy } \\
\text { informed by obesity } \\
\text { prevention science. }\end{array}$ & $\begin{array}{l}\text { Food marketing and } \\
\text { advertising environment } \\
\text { in economically } \\
\text { disadvantaged areas to } \\
\text { promote health and } \\
\text { prevent obesity. }\end{array}$ \\
\hline $\begin{array}{l}\text { Microenvironmental } \\
\text { setting }\end{array}$ & $\begin{array}{l}\text { Food retailers and food } \\
\text { service outlets determine } \\
\text { local healthy food } \\
\text { options. }\end{array}$ & $\begin{array}{l}\text { Institutional financial } \\
\text { support for health } \\
\text { promotion and nutrition } \\
\text { programs; financial } \\
\text { support for support } \\
\text { local food production. }\end{array}$ & $\begin{array}{l}\text { Institutional rules and } \\
\text { policies influencing } \\
\text { availability of healthy } \\
\text { food options. }\end{array}$ & $\begin{array}{l}\text { Institutional climate } \\
\text { around nutritious eating } \\
\text { and healthy body weight } \\
\text { maintenance. }\end{array}$ \\
\hline
\end{tabular}

the physical environment requires understanding the ways in which macroenvironmental physical factors including resource inputs, food production, distribution, and transportation systems influence the availability of healthy food venues by geographic region. Resource inputs refer to the raw materials, biophysical factors, and social factors available in a given environment for input into the food system. Food production involves transformation of resource inputs into raw agricultural goods, and food processing involves transformation of production output agricultural goods into food for distribution. Many low-income populations live in "food deserts" wherein failures in distribution result in geographic areas devoid of retail establishments offering healthy food options thereby limiting access to affordable, nutritious food in such neighborhoods $[67,68]$.

Opportunities for intervention in the macroenvironmental physical food environment may legislative efforts to modify existing agricultural, housing, transportation, and social policies to address the dual issues of food security and obesity prevention $[5,68]$. For example, currently retailers authorized to participate in SNAP are required to sell staple foods for home preparation and consumption and must offer on a continuous basis, at least three different varieties of foods from the four staple food categories, with at least two of the food categories being perishable foods [68]. Alternatively, authorized SNAP retailers must have more than half of their total gross sales from staple foods. This policy aims to increase access to healthy food options, although most SNAP retailers are authorized under the first criterion and therefore can meet said requirements by offering a small number and variety of staple food items [68]. Efforts are underway by the USDA to review current regulations with the goal of striking a balance to maintain an adequate supply of required foods while retaining retailer participation in SNAP [68]. Modifications to WIC food packages to include whole grains, fruits and vegetables, and reduced fat milk (versus whole milk) for children over 2 years of age have also been successful in improving the diets of WIC recipients [54, 57, 69]. Other policy level interventions at the macroenvironmental level that may influence the physical food environment include incorporation of community food access into housing and community development planning and transportation development and planning and related policy $[67,68]$.

Food distribution determines the local availability of points of access including wholesale or retail entities, the food service industry, and public and private food assistance programs and is therefore the vital link to consumer acquisition at the microenvironmental setting level. At the microenvironmental level, grassroots and local community food projects to improve availability of food options have shown promise in improving access and the dietary intake in at risk populations $[68,70]$. The USDA Community Food Projects Competitive Grants Program has funded hundreds of community food projects under the umbrella aim of supporting communities in local efforts to improve local food systems [70]. Examples of community food project activities may include: increasing the availability of locally produced, healthy food options through community gardens, farmers markets, and food assistance programs; improving dietary composition through nutrition education, cooking classes, and engagement in food production; increasing participation in nutrition programs; and working to integrate food system issues into community planning and local public health initiatives $[68,70]$. Although there is considerable diversity in community food projects as per the needs of diverse communities, a systematic review of five years of funded projects revealed the following shared aims of community food projects: they focus on the food needs of low-income populations; they aim to connect local food producers and consumers; they strive to increase the local food production and self-reliance; and they attempt to develop integrated solutions to agriculture, food, and nutrition-related problems [70]. These goals coincide with community food security and obesity prevention goals and strive to develop local food systems that promote health, sustainability, and community self-sufficiency.

Opportunities for intervention may also occur at the point of purchase, wherein the concept of optimal defaults could be applied to location of healthy food options in retail and wholesale settings to promote consumption [52]. 
Possibilities for dissemination of nutrition information also abound, with product and menu labeling, and in-store educational campaigns aimed at raising consumer awareness of healthy and affordable food options [71-73]. Addressing physical environment food system vulnerabilities requires identification of specific deficits in human and/or technological resources resulting in food system failure at the point of resource inputs, production, processing, distribution, or point of purchase (e.g., food labeling) that must be addressed in order to produce and distribute adequate and healthful food resources for a given population [63].

6.2. Economic Food Environment. The economic environment describes the costs related to food production, manufacturing, distribution, retailing, and purchase [66]. Economic factors at both the macro- and microenvironmental level are strongly related to both obesity and food insecurity $[2,38,40,44]$. Expansion of federal antipoverty initiatives, including food and nutrition assistance programs such as SNAP and WIC, school meal programs, the Head Start program, the Earned Income Tax Credit, and the Temporary Assistance for Needy Families program, may serve to improve access to healthy food options [48, 74-76].

Individuals may also lack the necessary resources, awareness, and/or skills to obtain consistent access to nutritious food. Monetary incentives, such as food subsidies, for production and consumption of healthy food options and monetary disincentives for the production and consumption of unhealthy food options, such as taxes, represent potentially powerful levers for change in both obesity prevention and food insecurity [66]. Other promising interventions to prevent obesity and reduce food insecurity may include institutional financial support for health promotion and nutrition programs and financial support to promote local food production efforts [68]. Efforts to incorporate nutrition education into existing programs, including school-based programs, Head Start, WIC, and SNAP, that reach at risk populations have been successful in improving nutritionrelated knowledge and behavior and are particularly encouraged [75-79].

6.3. Political Food Environment. The political food environment refers to the laws, regulations (macroenvironment), and institutional rules (microenvironment) that influence available food options and related individual behavior [66]. The political environment holds prominent opportunities for wide-spread change in population burden of food insecurity and obesity. As per our prior discussion of policy level interventions to influence the physical and economic food environments, agricultural, transportation, social legislation, and resultant food and nutrition policy informed by obesity prevention science and public health goals around food security could promote the health and well-being of the population [45]. At the macrolevel, additional regulatory forces in the political environment determine nutrition labeling standards, health claims on packages and in stores, and the nature of food advertisements aimed at youth. Packaging, labeling, and advertisement exert considerable influence on consumer behavior, and therefore represent significant levers for change in the political environment. At the microlevel, schools, hospitals, and workplaces may adopt policies regarding the nature of food services, including requirements for the quantities and qualities of foods served in cafeterias, vending machines, and other outlets $[80,81]$.

6.4. Sociocultural Food Environment. The sociocultural food environment refers to the social and cultural norms or beliefs, values, and attitudes about food, embraced by a community or society [66]. At the macroenvironmental level, food marketing and advertising can be leveraged as compelling interventions to promote health and prevent obesity. At the microenvironmental level, institutional climate around nutritious eating and healthy body weight maintenance can be targeted within specific settings (e.g., schools or worksites) to encourage and educate around healthful and affordable food options. Homes also represent an important microenvironmental context in which social and cultural norms about food are shaped. The home environment and parenting styles and practices, in particular, have received increasing attention with regard to the role that parents play in children's eating behaviors. For example, parents are not only responsible for the amounts and types of food made available in the home; they are the first socializing agent for children's eating. A large body of research has demonstrated that children's eating is shaped instrumentally by the foods that parents bring into the home and by modeling. A growing evidence base suggests that the ways in which parents go about attempting to shape children's eating is also important. For example, a parent may limit a child's junk food intake by restrictive practices such as not allowing certain foods in the home at all or vigilantly monitoring their child's eating behaviors. By comparison, a parent may also limit junk food intake by talking to the child about why salty and sugary snack foods are "sometimes" foods to be eaten only in small amounts or on special occasions. Evidence suggests that parental feeding practices that include behaviors such as providing age-appropriate rationales and some structure and limit settings (i.e., a middle ground between allowing children to make all of the decisions and forbidding eating some foods like junk food while demanding eating others like fruit and vegetables) result in children eating and selfregulating food intake better [82-84].

Although there is evidence that parental feeding styles and practices influence children's eating behaviors, less is known about the precursors to parental feeding styles and practices. Food insecurity may be one such factor. Indeed, when parents are food insecure it is likely that they will interact with their children around eating differently than if they are confident that they will have sufficient food for the next meal, the next day, or for the next month. For example, they may be more likely to encourage children to eat more when it is available, even after the child has indicated that he or she is full. Literature on the parental feeding practice of "clean your plate" (i.e., eat everything that is on your plate) indicates that this is one mechanism by which children stop paying attention to physiological cues of hunger and fullness 
and instead rely on cues in the physical environment [85]. More recent evidence suggests that pressuring children to eat may backfire in terms of children's food preferences, which has important implications not only for the quantity of foods consumed but for their quality [86]. Although food insecure parents may be engaging in this practice for good reason, the potential long-term consequences of encouraging children to eat past the physiological sense of fullness have important implications for eating regulation and obesity. Food insecure parents may also be more likely to purchase and serve foods that they are certain their children will eat (e.g., sugary or salty food), because they do not want to risk-wasting resources on foods that their children may not eat.

\section{Conclusion}

Increasing population burden of food insecurity and obesity speaks to the critical need for development of a comprehensive approach to reform existing food systems to simultaneously address issues of community food justice, food security, food quality, and public health success related to obesity prevention. Interventions that cultivate sustainable food systems to promote health, improve food security, and prevent obesity, with multiple social, ecological, and economic benefits, based on an ecological approach that conceptualizes the shared physical, economic, political, and sociocultural environments of obesity and food insecurity are needed. Current food insecurity initiatives and national obesity prevention public health goals could be coordinated through the adoption of a food systems approach to conduct strategic science to inform public health interventions aimed at improving population health through environmental and policy level changes to promote nutrition environments with optimal defaults to support individual behavior. Continued efforts are needed to systematically identify policy gaps and opportunities for and barriers to merging food security and obesity prevention initiatives, as part of an ongoing process of developing and implementing an integrated and comprehensive strategy for addressing the nutrition-related needs of at risk populations.

\section{Acknowledgments}

This paper was supported by funds from the Robert Wood Johnson Foundation through its Healthy Eating Research program. This project has been funded in part with federal funds from the National Cancer Institute, National Institutes of Health, under contract no. HHSN261200800001E. The content of this publication does not necessarily reflect the views or policies of the Department of Health and Human Services nor does mention of trade names, commercial products, or organizations imply endorsement by the USA Government.

\section{References}

[1] M. Nord, M. Andrews, and S. Carlson, Household Food Security in the United States, 2008, U.S. Department of Agriculture, Economic Research Service, Washington, DC, USA, 2009.
[2] K. Ball and D. Crawford, "Socio-economic factors in obesity: a case of slim chance in a fat world?" Asia Pacific Journal of Clinical Nutrition, vol. 15, supplement, pp. 15-20, 2006.

[3] N. I. Larson and M. T. Story, "Food insecurity and weight status among U.S. children and families: a review of the literature," American Journal of Preventive Medicine, vol. 40, no. 2, pp. 166-173, 2011.

[4] A. L. Yaroch and C. A. Pinard, "Are the hungry more at risk for eating calorie-dense nutrient-poor foods?: comment on "first foods most: after 18-hour fast, people drawn to starches first and vegetables last" the hungry eat calorie-dense nutrientpoor foods," Archives of Internal Medicine, vol. 172, no. 12, pp. 963-964, 2012.

[5] L. Dube, P. Pingali, and P. Webb, "Paths of convergence for agriculture, health, and wealth," Proceedings of the National Academy of Sciences, vol. 109, no. 31, pp. 12294-12301, 2012.

[6] R. A. Hammond and L. Dubé, "A systems science perspective and transdisciplinary models for food and nutrition security," Proceedings of the National Academy of Sciences, vol. 109, no. 31, pp. 12356-12363, 2012.

[7] J. Bhattacharya, J. Currie, and S. Haider, "Poverty, food insecurity, and nutritional outcomes in children and adults," Journal of Health Economics, vol. 23, no. 4, pp. 839-862, 2004.

[8] L. M. Dinour, D. Bergen, and M. C. Yeh, "The food insecurityobesity paradox: a review of the literature and the role food stamps may play," Journal of the American Dietetic Association, vol. 107, no. 11, pp. 1952-1961, 2007.

[9] NIH, "Clinical guidelines on the identification, evaluation, and Treatment of overweight and obesity in adults - the evidence report. National institutes of health," Obesity Research, vol. 6, supplement 2, pp. 51S-209S, 1998.

[10] CDC, "State-specific prevalence of obesity among adultsUnited States, 2007," Morbidity and Mortality Weekly Report, vol. 57, no. 28, pp. 765-768, 2008.

[11] A. H. Mokdad, M. K. Serdula, W. H. Dietz, B. A. Bowman, J. S. Marks, and J. P. Koplan, "The spread of the obesity epidemic in the United States, 1991-1998," Journal of the American Medical Association, vol. 282, no. 16, pp. 1519-1522, 1999.

[12] K. M. Flegal, M. D. Carroll, C. L. Ogden, and L. R. Curtin, "Prevalence and trends in obesity among US adults, 19992008," Journal of the American Medical Association, vol. 303, no. 3, pp. 235-241, 2010.

[13] K. M. Flegal, M. D. Carroll, C. L. Ogden, and L. R. Curtin, "Prevalence and trends in obesity among US adults, 19992008," Journal of the American Medical Association, vol. 303, no. 3, pp. 235-241, 2010.

[14] C. L. Ogden, M. D. Carroll, L. R. Curtin, M. M. Lamb, and K. M. Flegal, "Prevalence of high body mass index in US children and adolescents, 2007-2008," Journal of the American Medical Association, vol. 303, no. 3, pp. 242-249, 2010.

[15] M. Shields, M. D. Carroll, and C. L. Ogden, "Adult obesity prevalence in Canada and the United States," Tech. Rep. 56, National Center for Health Statistics Data Brief, 2011, http://www.cdc.gov/nchs/data/databriefs/db56.htm.

[16] S. J. Olshansky, D. J. Passaro, R. C. Hershow et al., "A potential decline in life expectancy in the United States in the 21st century," The New England Journal of Medicine, vol. 352, no. 11, pp. 1138-1145, 2005.

[17] G. K. Singh, M. D. Kogan, and P. C. Van Dyck, "Changes in state-specific childhood obesity and overweight prevalence in the United States from 2003 to 2007," Archives of Pediatrics and Adolescent Medicine, vol. 164, no. 7, pp. 598-607, 2010.

[18] M. H. Park, C. Falconer, R. M. Viner, and S. Kinra, "The impact of childhood obesity on morbidity and mortality in 
adulthood: a systematic review," Obesity Reviews, vol. 13, no. 11, pp. 985-1000, 2012.

[19] J. J. Reilly and J. Kelly, "Long-term impact of overweight and obesity in childhood and adolescence on morbidity and premature mortality in adulthood: systematic review," International Journal of Obesity, vol. 35, no. 7, pp. 891-898, 2011.

[20] M. Lenz, T. Richter, and I. Mühlhauser, "The morbidity and mortality associated with overweight and obesity in adulthood: a systematic review," Deutsches Arzteblatt, vol. 106, no. 40, pp. 641-648, 2009.

[21] M. Nord, M. Andrews, and S. Carlson, Household Food Security in the United States, 2007, U.S. Department of Agriculture, Economic Research Service, Washington, DC, USA, 2008.

[22] M. Nord, A. Coleman-Jensen, M. Andrews, and S. Carlson, Household Food Security in the United States, 2009, US Department of Agriculture, Economic Research Service, Washington, DC, USA, 2010.

[23] M. Nord, M. Andrews, and S. Carlson, Household Food Security in the United States, 2010, US Department of Agriculture, Economic Research Service, Washington, DC, USA, 2011.

[24] ERS, "The food assistance landscape: fiscal year 2010 annual report," Economic Information Bulletin 6-8, Economic Research Service, U.S. Department of Agriculture, Washington, DC, USA, 2011.

[25] P. H. Casey, P. M. Simpson, J. M. Gossett et al., "The association of child and household food insecurity with childhood overweight status," Pediatrics, vol. 118, no. 5, pp. e1406-e1413, 2006.

[26] P. H. Casey, K. Szeto, S. Lensing, M. Bogle, and J. Weber, "Children in food-insufficient, low-income families: prevalence, health, and nutrition status," Archives of Pediatrics and Adolescent Medicine, vol. 155, no. 4, pp. 508-514, 2001.

[27] P. B. Crawford and K. L. Webb, "Unraveling the paradox of concurrent food insecurity and obesity," American Journal of Preventive Medicine, vol. 40, no. 2, pp. 274-275, 2011.

[28] S. J. Jones and E. A. Frongillo, "Food insecurity and subsequent weight gain in women," Public Health Nutrition, vol. 10, no. 2, pp. 145-151, 2007.

[29] D. F. Jyoti, E. A. Frongillo, and S. J. Jones, "Food insecurity affects school children's academic performance, weight gain, and social skills," Journal of Nutrition, vol. 135, no. 12, pp. 2831-2839, 2005.

[30] A. Karnik, B. A. Foster, V. Mayer et al., "Food insecurity and obesity in New York City primary care clinics," Medical Care, vol. 49, no. 7, pp. 658-661, 2011.

[31] K. S. Martin and A. M. Ferris, "Food insecurity and gender are risk factors for obesity," Journal of Nutrition Education and Behavior, vol. 39, no. 1, pp. 31-36, 2007.

[32] E. Metallinos-Katsaras, B. Sherry, and J. Kallio, "Food insecurity is associated with overweight in children younger than 5 years of age," Journal of the American Dietetic Association, vol. 109, no. 10, pp. 1790-1794, 2009.

[33] A. F. Meyers, R. J. Karp, and J. G. Kral, "Poverty, food insecurity, and obesity in children," Pediatrics, vol. 118 , no. 5 , pp. 2265-2266, 2006.

[34] C. M. Olson and M. S. Strawderman, "The relationship between food insecurity and obesity in rural childbearing women," Journal of Rural Health, vol. 24, no. 1, pp. 60-66, 2008.

[35] J. Stuff et al., "Household food insecurity and obesity, chronic disease, and chronic disesase risk factors," Journal of Hunger \& Environmental Nutrition, vol. 1, no. 2, pp. 43-61, 2006.

[36] R. C. Whitaker and A. Sarin, "Change in food security status and change in weight are not associated in urban women with preschool children," Journal of Nutrition, vol. 137, no. 9, pp. 2134-2139, 2007.

[37] P. E. Wilde and J. N. Peterman, "Individual weight change is associated with household food security status," Journal of Nutrition, vol. 136, no. 5, pp. 1395-1400, 2006.

[38] V. Shrewsbury and J. Wardle, "Socioeconomic status and adiposity in childhood: a systematic review of cross-sectional studies 1990-2005," Obesity, vol. 16, no. 2, pp. 275-284, 2008.

[39] Y. Wang and M. A. Beydoun, "The obesity epidemic in the United States-gender, age, socioeconomic, racial/ethnic, and geographic characteristics: a systematic review and metaregression analysis," Epidemiologic Reviews, vol. 29, no. 1, pp. 6-28, 2007.

[40] P. M. Lantz, J. S. House, J. M. Lepkowski, D. R. Williams, R. P. Mero, and J. Chen, "Socioeconomic factors, health behaviors, and mortality: results from a nationally representative prospective study of US adults," Journal of the American Medical Association, vol. 279, no. 21, pp. 1703-1708, 1998.

[41] B. A. Laraia, A. M. Siega-Riz, C. Gundersen, and N. Dole, "Psychosocial factors and socioeconomic indicators are associated with household food insecurity among pregnant women," Journal of Nutrition, vol. 136, no. 1, pp. 177-182, 2006.

[42] G. K. Singh, M. D. Kogan, and S. M. Yu, "Disparities in obesity and overweight prevalence among us immigrant children and adolescents by generational status," Journal of Community Health, vol. 34, no. 4, pp. 271-281, 2009.

[43] G. K. Singh, M. Siahpush, and M. D. Kogan, "Rising Social Inequalities in US childhood obesity, 2003-2007," Annals of Epidemiology, vol. 20, no. 1, pp. 40-52, 2010.

[44] G. Enzi, "Socioeconomic consequences of obesity: the effect of obesity on the individual," PharmacoEconomics, vol. 5, supplement 1, pp. 54-57, 1994.

[45] M. Story, M. W. Hamm, and D. Wallinga, "Food systems and public health: linkages to achieve healthier diets and healthier communities," Journal of Hunger and Environmental Nutrition, vol. 4, no. 3-4, pp. 219-224, 2009.

[46] L. J. F. Rutten, A. L. Yaroch, U. Colón-Ramos, W. JohnsonAskew, and M. Story, "Poverty, food insecurity, and obesity: a conceptual framework for research, practice, and policy," Journal of Hunger and Environmental Nutrition, vol. 5, no. 4, pp. 403-415, 2010.

[47] M. Kursmark and M. Weitzman, "Recent findings concerning childhood food insecurity," Current Opinion in Clinical Nutrition and Metabolic Care, vol. 12, no. 3, pp. 310-316, 2009.

[48] M. V. Ploeg, L. Mancino, B. H. Lin, and J. Guthrie, "US food assistance programs and trends in children's weight," International Journal of Pediatric Obesity, vol. 3, no. 1, pp. 22-30, 2008.

[49] E. A. Frongillo, "Understanding obesity and program participation in the context of poverty and food insecurity," Journal of Nutrition, vol. 133, no. 7, pp. 2117-2118, 2003.

[50] USDA, The food Assistance Landscape: FY 2011 Annual Report, USDA, Washington, DC, USA, 2012.

[51] J. F. Guthrie, E. Frazao, M. Andrews, and D. Smallwood, Improving Food Choices-Can Food Stamps Do More? Perspectives on Food and Farm Policy: Food and Nutrition in Amberwaves, U.S. Department of Agriculture, Economic Research Service, Washington, DC, USA, 2007.

[52] R. H. Thaler and C. R. Sunstein, Nudge: Improving Decisions on Health, Wealth, and Happiness, Yale University Press, New Haven, Conn, USA, 2008.

[53] A. S. Hanks, D. R. Just, L. E. Smith, and B. Wansink, "Healthy convenience: nudging students toward healthier choices in 
the lunchroom," Journal of Public Health, vol. 34, no. 3, pp. 370-376, 2012.

[54] A. Hillier, J. McLaughlin, C. C. Cannuscio, M. Chilton, S. Krasny, and A. Karpyn, "The impact of WIC food package changes on access to healthful food in 2 low-income urban neighborhoods," Journal of Nutrition Education and Behavior, vol. 44, no. 3, pp. 210-216, 2012.

[55] J. E. Painter, B. Wansink, and J. B. Hieggelke, "How visibility and convenience influence candy consumption," Appetite, vol. 38, no. 3, pp. 237-238, 2002.

[56] B. Wansink, "Environmental factors that increase the food intake and consumption volume of unknowing consumers," Annual Review of Nutrition, vol. 24, pp. 455-479, 2004.

[57] S. E. Whaley, L. D. Ritchie, P. Spector, and J. Gomez, "Revised WIC food package improves diets of WIC families," Journal of Nutrition Education and Behavior, vol. 44, no. 3, pp. 204-209, 2012.

[58] USDHHS, Healthy People 2020 Nutrition and Weight Status Objectives, Office of Disease Prevention and Health Promotion, U.S. Department of Health and Human Services, Washington, DC, USA, 2010.

[59] WHTF, Report to the President: Solving the Problem of Childhood Obesity within a Generation, White House Task Force on Childhood Obesity (WHTF), 2010.

[60] WHTF, Report to the President: Solving the Problem of Childhood Obesity within a Generation, One Year Progress Report, White House Task Force on Childhood Obesity (WHTF), 2011.

[61] USDHHS, Strategic Plan for NIH Obesity Research: A Report of the NIH Obesity Research Task Force, U.S. Department of Health and Human Services, National Institutes of Health, Washington, DC, USA, 2011.

[62] APHA, "Toward a healthy, sustainable food system," in American Public Health Association Policy Statement Database, American Public Health Association, 2007.

[63] ADA AMA. APA, A., Principles of a healthy, sustainable food system, American Dietetic Association, the American Nurses Association, The American Planning Association, and the American Public Health Association, 2010.

[64] C. Hawkes, "Identifying innovative interventions to promote healthy eating using consumption-oriented food supply chain analysis," Journal of Hunger and Environmental Nutrition, vol. 4, no. 3-4, pp. 336-356, 2009.

[65] G. Egger, S. Pearson, S. Pal, and B. Swinburn, "Dissecting obesogenic behaviours: the development and application of a test battery for targeting prescription for weight loss," Obesity Reviews, vol. 8, no. 6, pp. 481-486, 2007.

[66] T. Giang, A. Karpyn, H. B. Laurison, A. Hillier, and R. D. Perry, "Closing the grocery gap in underserved communities: the creation of the Pennsylvania fresh food financing initiative," Journal of Public Health Management and Practice, vol. 14, no. 3, pp. 272-279, 2008.

[67] J. Beaulac, E. Kristjansson, and S. Cummins, "A systematic review of food deserts, 1966-2007," Preventing Chronic Disease, vol. 6, no. 3, p. A105, 2009.

[68] M. Ver Ploeg, V. Breneman, T. Farrigan et al., "Access to affordable and nutritious food-measuring and understanding food deserts and their consequences: report to congress," in Administrative Publication, USDA, Economic Research Service, 2009.

[69] WIC, Revisions in the WIC Food Packages, Special Supplemental Nutrition Program for Women, Infants and Children (WIC), 2007.
[70] K. Pothukuchi, Building Community Food Security: Lessons from Community Food Projects, 1999-2003, 2007.

[71] G. X. Ayala, M. N. Laska, S. N. Zenk et al., "Stocking characteristics and perceived increases in sales among small food store managers/owners associated with the introduction of new food products approved by the special supplemental nutrition program for women, infants, and children," Public Health Nutrition, vol. 14, pp. 1-9, 2012.

[72] N. C. Crespo, J. P. Elder, G. X. Ayala et al., "Results of a multilevel intervention to prevent and control childhood obesity among latino children: the aventuras para ninos study," Annals of Behavioral Medicine, vol. 43, no. 1, pp. 84-100, 2012.

[73] J. Gittelsohn, M, N. Laska, T. Andreyeva et al., "Small retailer perspectives of the 2009 women, infants and children program food package changes," American Journal of Health Behavior, vol. 36, no. 5, pp. 655-665, 2012.

[74] R. A. Gooze, C. C. Hughes, D. M. Finkelstein, and R. C. Whitaker, "Reaching staff, parents, and community partners to prevent childhood obesity in head start, 2008," Preventing Chronic Disease, vol. 7, no. 3, p. A54, 2010.

[75] C. C. Hughes, R. A. Gooze, D. M. Finkelstein, and R. C. Whitaker, "Barriers to obesity prevention in head start," Health Affairs, vol. 29, no. 3, pp. 454-462, 2010.

[76] R. C. Whitaker, R. A. Gooze, C. C. Hughes, and D. M. Finkelstein, "A national survey of obesity prevention practices in head start," Archives of Pediatrics and Adolescent Medicine, vol. 163, no. 12, pp. 1144-1150, 2009.

[77] R. A. Gooze, C. C. Hughes, D. M. Finkelstein, and R. C. Whitaker, "Reaching staff, parents, and community partners to prevent childhood obesity in head start, 2008," Preventing chronic disease, vol. 7, no. 3, p. A54, 2010.

[78] D. E. Wall, C. Least, J. Gromis, and B. Lohse, "Nutrition education intervention improves vegetable-related attitude, selfefficacy, preference, and knowledge of fourth-grade students," Journal of School Health, vol. 82, no. 1, pp. 37-43, 2012.

[79] B. MkNelly, S. Nishio, C. Peshek, and M. Oppen, "Community health centers: a promising venue for supplemental nutrition assistance program education in the central valley," Journal of Nutrition Education and Behavior, vol. 43, no. 4, supplement 2, pp. S137-S144, 2011.

[80] M. S. Nanney, T. Nelson, M. Wall et al., "State school nutrition and physical activity policy environments and youth obesity," American Journal of Preventive Medicine, vol. 38, no. 1, pp. 916, 2010.

[81] M. Story, M. S. Nanney, and M. B. Schwartz, "Schools and obesity prevention: creating school environments and policies to promote healthy eating and physical activity," Milbank Quarterly, vol. 87, no. 1, pp. 71-100, 2009.

[82] A. K. Ventura and L. L. Birch, "Does parenting affect children's eating and weight status?" International Journal of Behavioral Nutrition and Physical Activity, vol. 5, article 15, 2008.

[83] H. R. Clark, E. Goyder, P. Bissell, L. Blank, and J. Peters, "How do parents' child-feeding behaviours influence child weight? Implications for childhood obesity policy," Journal of Public Health, vol. 29, no. 2, pp. 132-141, 2007.

[84] J. S. Savage, J. O. Fisher, and L. L. Birch, "Parental influence on eating behavior: conception to adolescence," Journal of Law, Medicine and Ethics, vol. 35, no. 1, pp. 22-34, 2007.

[85] L. L. Birch and J. O. Fisher, "Development of eating behaviors among children and adolescents," Pediatrics, vol. 101, no. 3, pp. 539-549, 1998. 
[86] A. T. Galloway, L. M. Fiorito, L. A. Francis, and L. L. Birch, "'Finish your soup': counterproductive effects of pressuring children to eat on intake and affect," Appetite, vol. 46, no. 3, pp. 318-323, 2006. 


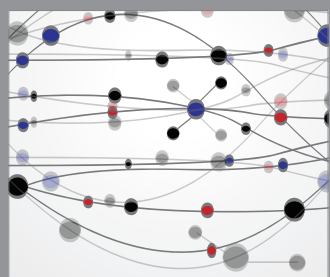

The Scientific World Journal
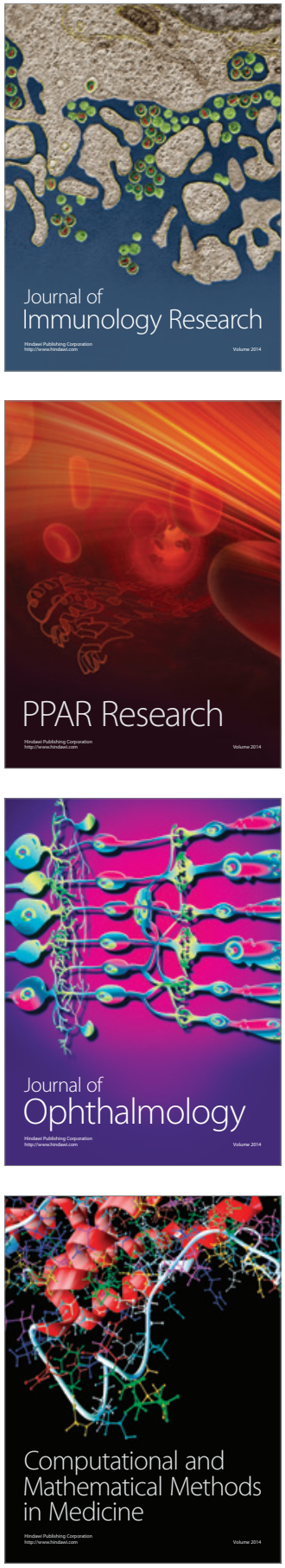

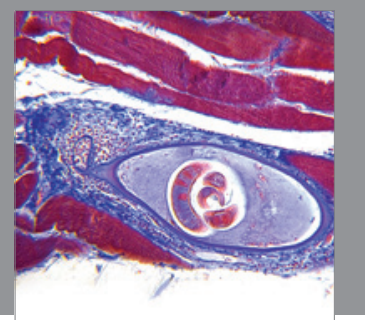

Gastroenterology

Research and Practice
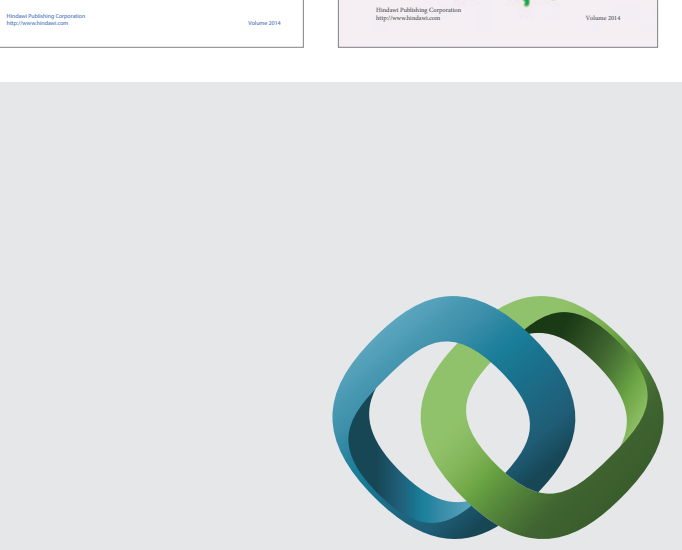

\section{Hindawi}

Submit your manuscripts at

http://www.hindawi.com
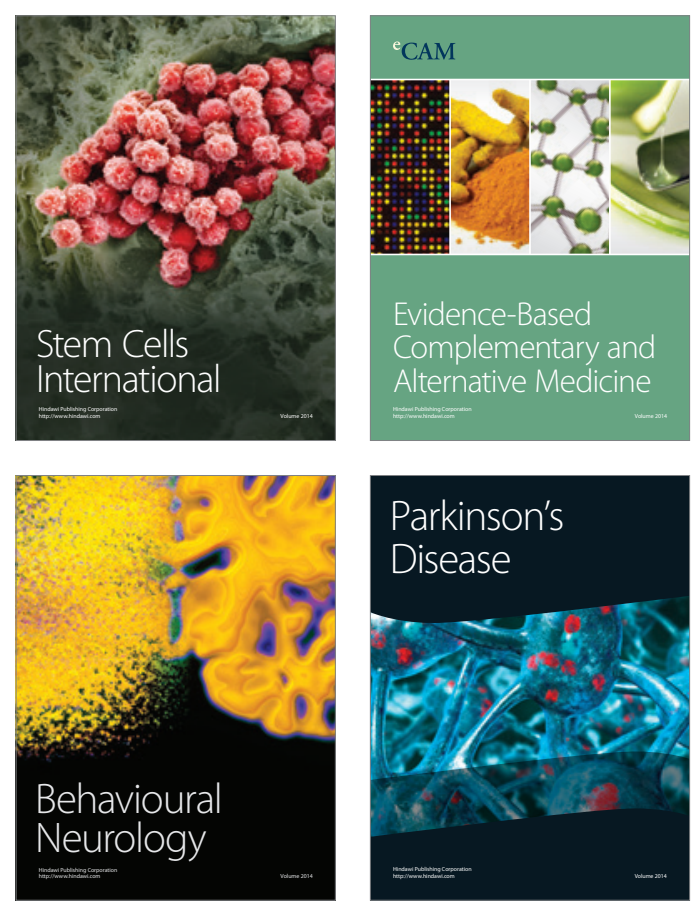

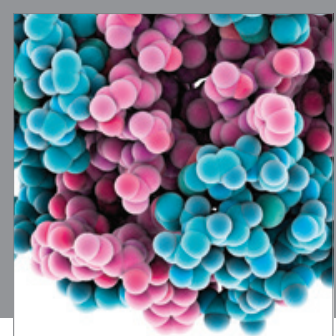

Journal of
Diabetes Research

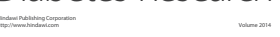

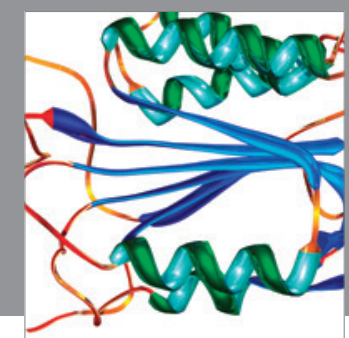

Disease Markers
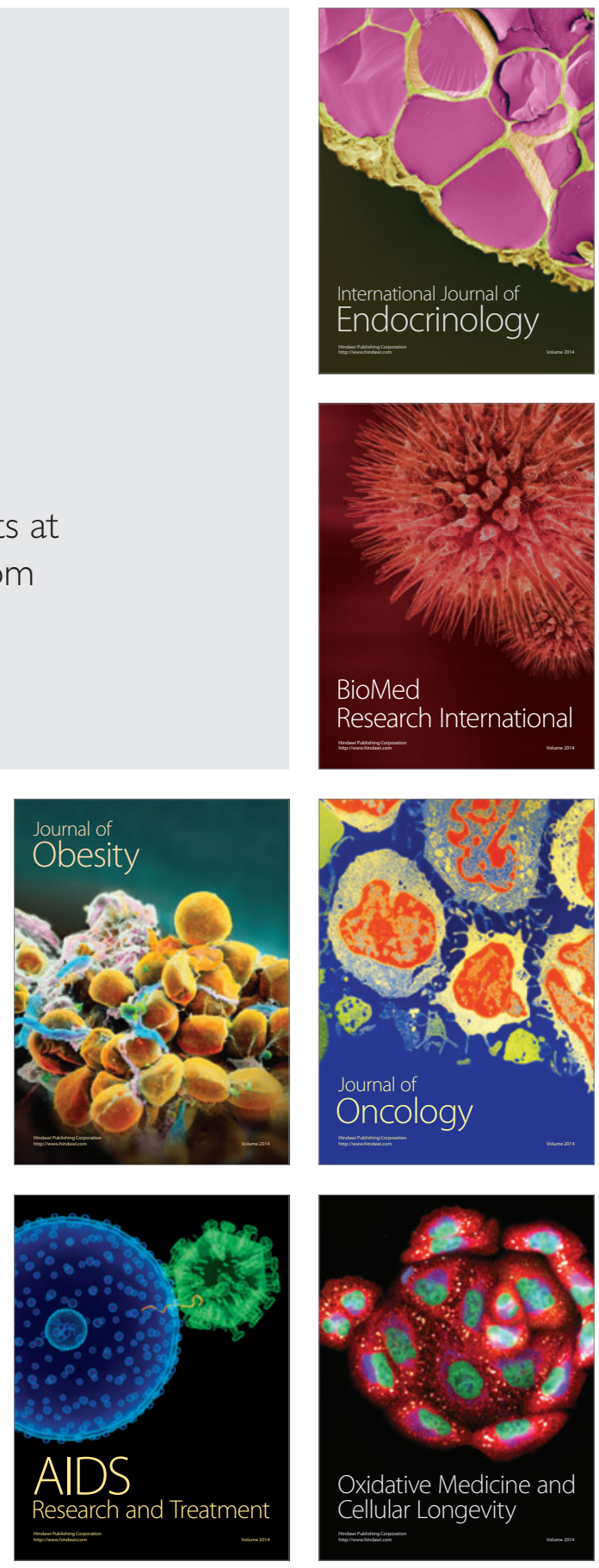